\title{
ENDOTHELIAL PROTEIN C RECEPTOR EXPRESSION IS REGULATED BY SP1 TRANSCRIPTION FACTOR IN MURINE MICROGLIA
}

\author{
Kemal Ugur Tufekci ${ }^{1}$, Halil Ates ${ }^{2}$, Sermin Genc ${ }^{3,4}$ \\ ${ }^{1}$ Izmir Democracy University, Vocational School of Health Services, Department of Healthcare Services, Izmir, Turkey. \\ 2 Dokuz Eylul University, Institute of Oncology, Department of Clinical Oncology, Izmir, Turkey. \\ ${ }^{3}$ Izmir Biomedicine and Genome Center, Balcova, Izmir, Turkey. \\ ${ }^{4}$ Dokuz Eylul University, Institute of Health Sciences, Department of Neuroscience, Izmir, Turkey
}

Address for Correspondence: Asst. Prof. Kemal Ugur Tufekci, E-mail: kemalugur.tufekci@idu.edu.tr Received: 06.01.2021; Accepted: 08.02.2021; Available Online Date: 04.03.2021

(C) Copyright 2021 by Dokuz Eylül University, Institute of Health Sciences - Available online at https://dergipark.org.tr/en/pub/jbachs

Cite this article as: Tufekci KU, Ates H, Genc S. Endothelial Protein C Receptor Expression is Regulated by Sp1 Transcription Factor in Murine Microglia. J Basic Clin Health Sci 2021; 1: 6-13.

\begin{abstract}
Objectives: Microglial cells are the central regulators of inflammatory responses in the brain and spinal cord. In addition to surveillance during resting state, they become activated due to microbial molecules and pathological insults. Endogenously expressed Activated protein $C$ (APC) is an anticoagulant molecule with anti-inflammatory and cytoprotective roles, mediated by one of its receptors, Endothelial protein $C$ receptor (EPCR). This study aimed to examine the basal and inducible expression of EPCR and unravel the regulatory mediators of its expression in microglia.

Methods: We studied probable effects of Lipopolysaccharide (LPS), Peptidoglycan (PGN), and Polyinosinic-polycytidylic acid [Poly(I:C)] on EPCR mRNA and protein levels in N9 mouse microglial cells by qPCR and flow cytometry. Then, Cyclosporin A (CsA) and Mithramycin A (MMA) were used to inhibit the transcription factors; i) Nuclear factor of activated T-cells, cytoplasmic 1 (NFATC1), and ii) specificity protein 1 (Sp1) in the promoter region of the EPCR gene.

Results: As a result, LPS and PGN stimulations led to the upregulation of EPCR expression in microglial cells. Inhibition of Sp1 and NFATc1 transcription factors in N9 cells showed that Sp1 transcription factor regulates LPS and PGN induced EPCR expression in N9 microglial cells. Also, for the PGN induced cells, NFATc1 seems to be regulating the expression of EPCR.

Conclusion: Thus, our data suggest that LPS and PGN gave rise to increased EPCR levels in microglia, mainly through the Sp1 transcription factor.
\end{abstract}

Keywords: Microglia, endothelial protein c receptor, lipopolysaccharide, peptidoglycan, Sp1 transcription factor

\section{INTRODUCTION}

Activated protein $C(A P C)$ is a natural anticoagulant protein derived from Vitamin-K dependent zymogen, Protein $C \quad(P C)$. Upon binding thrombin to thrombomodulin on the endothelial cell surface, the
PC is modified to APC (1). APC regulates blood coagulation by factor Va and VIIla inhibition if plasma protein $S$ is present and repressing thrombin generation (2). APC pathway is initiated by Endothelial Protein C Receptor (EPCR), and 
Proteinase activated receptors (PARs) in a cell lineage dependent manner $(2,3)$. EPCR is broadly expressed on large vessel endothelium (4). In addition to large vessel endothelium, EPCR is widely expressed by a variety of cells, such as immune cells (monocytes and neutrophils), muscle tissue cells (smooth muscle cells and cardiomyocytes), keratinocytes, placental trophoblasts, and neurons (5). It also exists in some precursor cells of hematopoietic, neuronal, and epithelial progenitor cells and breast cancer stem cells $(6,7)$.

Despite crucial roles in blood coagulation, APC also has anti-inflammatory properties related to the decrease of pro-inflammatory cytokines and leukocyte recruitment $(8,9)$, mostly organized via EPCR signaling $(4,10)$. The deficiency of EPCR has already been vital for survival and cardiac function in endotoxin-treated mice (10). On the contrary, EPCR over-expressing transgenic mice are protected against endotoxemia (11). The protective effects of APC also require another cell surface receptor, PAR1. Upon APC binding to EPCR, PAR-1 is activated to induce protective signaling pathways for endothelial integrity, inhibition of apoptosis, and antiinflammatory effects $(12,13)$. Although PAR-1 is a receptor for Thrombin and activates pro-inflammatory mechanisms, PAR-1 also mediates anti-inflammatory processes while EPCR is bound to its natural ligand APC (14). EPCR is mostly located on the cell surface, while a small amount of it is located in the intracellular recycling compartment (15). Upon ligand binding to EPCR, endocytosis is internalized into the recycling compartment to activate intracellular signaling cascade through Rab GTPases (16).

In the central nervous system, the APC pathway regulates apoptosis and inflammation, and it has been shown to have anti-inflammatory and cytoprotective effects in neural cells (17). Besides, APC also directly protects neurons from neurotoxicity in vitro and in vivo via EPCR and PAR-1. Following transient brain ischemia in mice, APC administration recovers the brain damage through PAR-1 dependent manner (18). APC has been reported to reduce infarct volume and recovered brain functions in animal models of cerebral ischemia (19). Furthermore, APC protects cortical neurons from N-methyl-D-aspartate (NMDA) and staurosporine-induced apoptosis via PAR-1 and -3 activation (20). Moreover, in the mSOD1 mouse model of Amyotrophic Lateral
Sclerosis (ALS), APC was also recovered ALS-like symptoms through of Sp1 transcription factor (21). Given all neuroprotective properties mentioned so far, one may suppose that EPCR could be considered an endogenous regulator of neuroinflammation. However, whether EPCR is expressed by microglial cells has not been reported. Since its ability to cross the blood-brain barrier (22), APC, the ligand of EPCR, is a promising drug target in neurodegenerative disorders. Although upregulation of EPCR appears to be beneficial and well-tolerated, it is not physiologically upregulated by nature. Thus, the aim of this study was: (1) to reveal EPCR expression in microglial cells; (2) to determine the effects of gramnegative and gram-positive cell wall components as inflammatory stimuli on EPCR expression and (3) to elicit the regulatory transcription factor on EPCR expression in microglial cells.

\section{METHODS \\ Reagents}

RPMI 1640 medium, Dulbecco's Modified Eagle's Medium (DMEM) with $4500 \mathrm{mg} / \mathrm{L}$ glucose, and Fetal bovine serum (FBS) were purchased from Gibco (CA, USA). L-Glutamine, Penicillin/Streptomycin, Phosphate buffered saline (PBS), Trypsin/EDTA were purchased from Biochrom (Germany). Cyclosporin A (CsA), Lipopolysaccharide (LPS, E. coli 055:B5), Mithramycin A (MMA), Peptidoglycan (PGN, from Staphylococcus aureus), and Polyinosinic-polycytidylic acid [Poly(l:C)] were from Sigma-Aldrich (Missouri, USA).

\section{Cell Culture and treatments}

The murine microglial cell line N9 was kindly provided by Prof. Paola Ricciardi-Castagnoli (Cellular Pharmacology Center, Milan, Italy). The cell line was established by immortalizing E13 mouse embryonic cultures by $\mathrm{V}$-Myc oncogene overexpression and displaying characteristics of primary microglia upon inflammatory insults (23). Cells were grown in RPMI 1640 medium supplemented with $10 \%$ FBS, $2 \mathrm{mM}$ LGlutamine, $100 \mathrm{U} / \mathrm{ml}$ penicillin, and $100 \mu \mathrm{g} / \mathrm{ml}$ streptomycin $37^{\circ} \mathrm{C}$ in humidified $5 \%$ CO2. As a positive control of EPCR expression, Raw264.7 cells were used (ATCC, TIB-71). Raw 264.7 cells were grown in DMEM medium supplemented with $10 \%$ FBS, 4mM L-Glutamine, $100 \mathrm{U} / \mathrm{ml}$ penicillin, and 100 $\mu \mathrm{g} / \mathrm{ml}$ streptomycin $37^{\circ} \mathrm{C}$ in humidified $5 \% \mathrm{CO} 2$. Cells were subcultured twice a week in a split ratio of 1:10. Cells were treated with $100 \mathrm{ng} / \mathrm{ml}$ LPS, $10 \mu \mathrm{g} / \mathrm{ml}$ 
PGN, or $10 \mu \mathrm{g} / \mathrm{ml}$ Poly(l:C) for inflammatory induction to model inflammation with gram-negative bacteria, gram-positive bacteria, virus, respectively. Furthermore, to inhibit the activity of Sp1 and NFATc1 transcription factors, $1 \mu \mathrm{M}$ MMA and $3 \mu \mathrm{M}$ CsA, respectively, were used 30 minutes before inflammatory agent treatments.

\section{Quantitative PCR}

N9 microglial cells were seeded at a density of $1 \times 106$ into $25 \mathrm{~cm} 2$ flasks to determine changes in the mRNA levels of the EPCR. Following treatments of N9 cells, total RNA isolation was performed by Nucleospin RNA II kit (Macherey-Nagel, Germany) according to the manufacturer's instructions. CDNA was synthesized by Revert-Aid CDNA synthesis kit (Thermo, USA) using $5 \mu \mathrm{g}$ of total RNA with random hexamer primer. The sequences of PCR primers used for the amplification were as follows: EPCR sense: 5'-AGCCAAACAGGTCGCTCTTA-3" antisense: 5'-AGTCCAGCCCTTTCTCCAAG-3" GAPDH sense: 5'-TCCACCCTGTTGCTGTA-3" antisense: 5" ACCACAGTCCATGCCATCAC-3" PCR amplification of the template cDNAs were performed using the following conditions for 40 cycles using LightCycler 480 SYBR Green I Master Mix (Roche, Switzerland). After initial denaturation at $95^{\circ} \mathrm{C}$ for 10 min, temperature cycling of denaturation at $95^{\circ} \mathrm{C}$ for $10 \mathrm{sec}$, annealing at $60^{\circ} \mathrm{C}$ for $10 \mathrm{sec}$, and extension at $72^{\circ} \mathrm{C}$ for $20 \mathrm{sec}$ were performed. PCR products were analyzed using melting curve analysis. Changes in the mRNA levels were analyzed relatively according to the comparative threshold cycle $(\triangle \triangle C T)$ method with endogenous normalization to GAPDH (24).

\section{EPCR Staining}

N9 cells were seeded onto poly-L-lysine coated 4chamber slides (Nunc, USA) at a density of $2 \times 104$ cells/chamber. Cells were fixed by $4 \%$ paraformaldehyde for $10 \mathrm{~min}$, blocked with $3 \%$ bovine serum albumin (BSA) in PBS for $30 \mathrm{~min}$, and incubated with anti-EPCR (RCR-252) (1:25 dilution) antibody (Abcam, USA) in 1\% BSA in PBS for $30 \mathrm{~min}$. After three washes with PBS, cells were incubated with Fluorescein isothiocyanate (FITC) conjugated chicken anti-rat $\lg G(1: 100)$ for 30 min. Finally, after three washes with PBS, cells were mounted with antifade reagent including 4',6-diamidino-2phenylindole (DAPI; Millipore) for counterstaining and observed with BX50 fluorescent microscope (Olympus, Japan).

\section{FACS analysis of EPCR levels}

N9 cells were seeded at 6 -well plates at a density of $2.5 \times 105$ cells/well. Following treatments, cells were harvested by trypsinization. Cells were washed twice in PBS, containing $0.5 \%$ BSA. After pelleting, cells were incubated with $10 \mu \mathrm{g} / \mathrm{ml}$ anti-EPCR (RCR-252) antibody or isotype-matched control IgG (BD Biosciences, USA) for 30 minutes at $4^{\circ} \mathrm{C}$. Cells were washed once in PBS, containing $0.5 \%$ BSA. After washing, $10 \mu \mathrm{g} / \mathrm{ml}$ FITC-conjugated goat anti-rat lgG (BD Biosciences, USA) was incubated for another 30 minutes at $4^{\circ} \mathrm{C}$. Cells were washed twice in PBS, containing $0.5 \%$ BSA, and immediately analyzed with BD FACS Canto II flow cytometer. Cells (104) were routinely counted, and cell population was defined regarding forward-side scatter characteristics.

\section{Statistical Analysis}

Statistical analyses were performed using GraphPad Prism 8.0 (GraphPad Software Inc., CA, USA). Data analyses were performed with one-way ANOVA with Bonferroni multiple comparison correction. $P$ values $<0.05$ were considered statistically significant. Each experiment was performed in five technical replicates and repeated three times.

\section{RESULTS}

\section{EPCR is expressed in Microglia}

To determine whether N9 microglial cells expressed EPCR, we used RT-PCR with a pair of primers designed for the EPCR gene. We used 40 PCR cycles to detect even low abundance transcripts. Our analysis shows that EPCR is expressed in N9 microglial cells and Raw 264.7 macrophages, positive control for EPCR expression, at varying detection levels (Figure 1A). Furthermore, the protein expression of EPCR was analyzed by fluorescent staining and flow cytometry. EPCR protein was detected at moderate amounts (Figure $1 \mathrm{~B}$ and $\mathrm{C}$ ).

\section{Inflammatory stimulants upregulate EPCR expression \\ EPCR protein expression in $\mathrm{N} 9$ cells upon inflammatory stimulation with LPS $(100 \mathrm{ng} / \mathrm{ml}), \mathrm{PGN}$ $(10 \mu \mathrm{g} / \mathrm{ml})$, and Poly $(\mathrm{l}: \mathrm{C})(10 \mu \mathrm{g} / \mathrm{ml})$ was analyzed with flow cytometry. LPS and PGN caused}




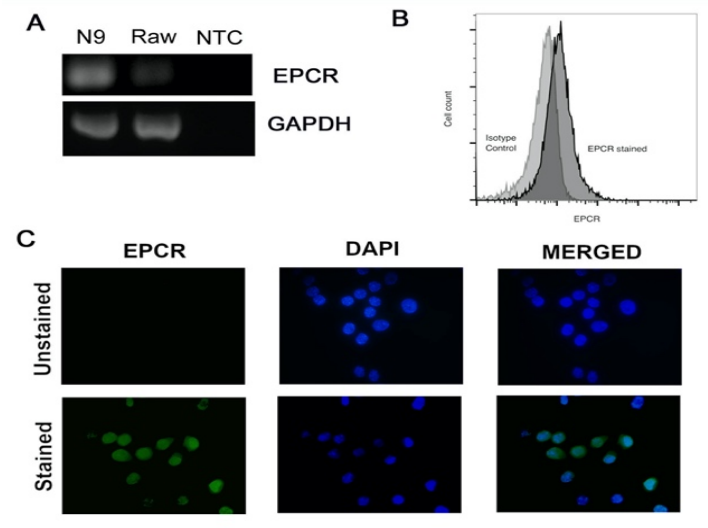

Figure 1. Microglial cells express EPCR. (A) EPCR expression in microglia and macrophage was analyzed by RT-PCR. Total RNA from N9 and positive control Raw 264.7 macrophages was isolated. Gene-specific products for Epcr and Gapdh were amplified by RT-PCR, separated by agarose gel electrophoresis, and visualized using a digital gel documentation system. (B) EPCR expression in N9 microglia was analyzed by flow cytometry. Cells were stained with EPCR antibody (dark line) or isotype controls (grey line). (C) N9 cells expressed EPCR (in green) under unstimulated conditions. Cells were counterstained with DAPI (nuclei in blue). Magnification 100X.
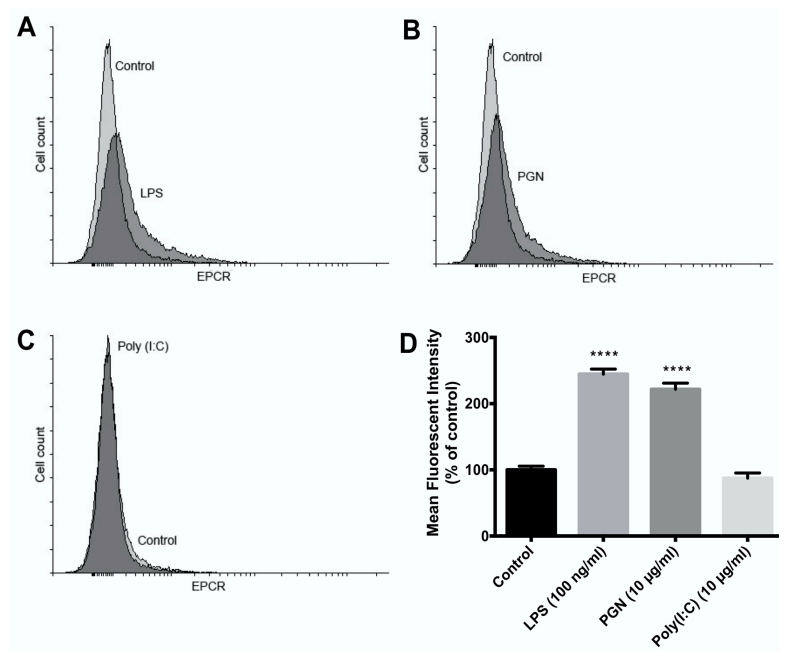

Figure 2. Effect of inflammatory stimuli on EPCR expression in N9 microglial cells. (A-C) EPCR protein levels were measured by flow cytometry upon stimulation by LPS, PGN, and Poly(I:C), respectively. (D) Mean fluorescent intensity of EPCR levels upon inflammatory stimuli. Data are expressed as mean \pm SEM $(n=3) .{ }^{* * * *} p<0.0001$ vs. control.

upregulation of EPCR protein levels by 2.45 -fold and 2.22 -fold ( $p<0.0001$ for both treatments). However, the poly $(\mathrm{l}: \mathrm{C})$ treatment resulted in a 0.87 -fold change of EPCR protein expression ( $p=0.7945)$ (Figure 2).

Following confirmation of potential EPCR upregulating effects of LPS and PGN, we aimed to elucidate the effect of the time on EPCR mRNA

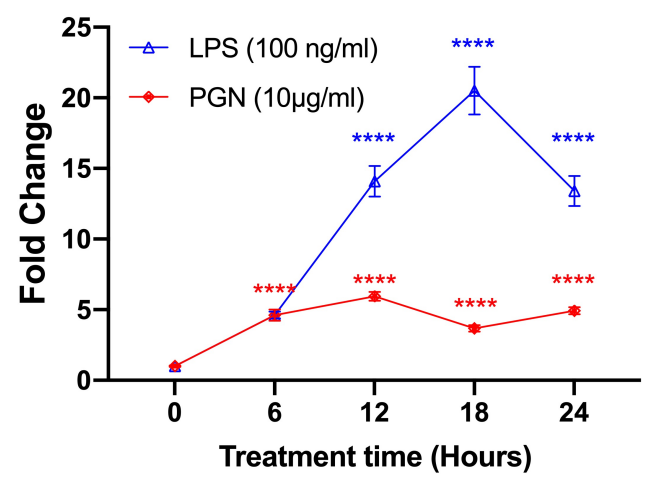

Figure 3: EPCR mRNA levels were upregulated in microglial cells by LPS or PGN. N9 cells were untreated or treated with LPS (100 $\mathrm{ng} / \mathrm{ml})$ and PGN $(10 \mu \mathrm{g} / \mathrm{ml})$ up to $24 \mathrm{~h}$, and EPCR mRNA levels upon treatment were analyzed by qPCR. Data are expressed as mean \pm SEM $(n=3)$. ${ }^{\star \star \star \star} p<0.0001$ vs 0 hour.

levels. Therefore, N9 microglia were stimulated with LPS and PGN for up to 24 hours. LPS stimulation caused 20.51-fold upregulation of EPCR at 18 hours $(p<0.0001)$. On the other hand, PGN caused steady upregulation of EPCR between 6-24 hours, approximately 4-fold $(p=0.0014)$ (Figure 3). Therefore, N9 cells were treated with PGN or LPS for $18 \mathrm{~h}$ for further experiments.

\section{Transcriptional regulators of EPCR upregulation}

After determination of EPCR upregulation, we aimed to reveal the underlying transcriptional regulatory mechanism. Since the nuclear factor of activated $T$ cells cytoplasmic 1 (NFATc1) and Specificity protein 1 (Sp1) are known as the master regulators of Epcr $(25,26)$, we utilized chemical inhibitors, namely Cyclosporin (CsA) and Mithramycin A (MMA) against NFATc1 and Sp1, respectively. Then, we analyzed both mRNA and protein levels of EPCR. Our flow cytometry analysis showed that LPS treatment resulted in a 7.44-fold increase in protein level $(p<0.0001)$ (Figure 4A). CsA and MMA's inhibitor conditions caused a 0.93 and 0.47 -fold decrease ( $p>0.9999$ and $p<0.0001$, respectively) of upregulated EPCR protein (Figure 4A-C). Furthermore, LPS incubation caused a 46.85 -fold increase of EPCR mRNA ( $p<0.0001)$, and inhibition by CsA and MMA resulted in 1.07 and 0.63 -fold ( $p>0.9999$ and $p<0.0001$, respectively) change of LPS induced EPCR mRNA levels (Figure 4D). Moreover, PGN treatment resulted in a 3.29-fold increase in protein level $(p<0.0001)$ (Figure $5 A)$. In inhibitor conditions, CsA and MMA caused a 1.16 and 0.53-fold decrease $(p=0.0559$ and $p<0.0001$, 
respectively) of upregulated EPCR protein (Figure $5 A-C)$. Furthermore, $P G N$ incubation caused a 20.64fold increase of EPCR mRNA $(p<0.0001)$, and inhibition by CsA and MMA caused downregulation of EPCR mRNA fold levels to $6.66(p<0.0001)$ and 14.69 $(p=0.0038)$, respectively. (Figure $5 D)$.

A
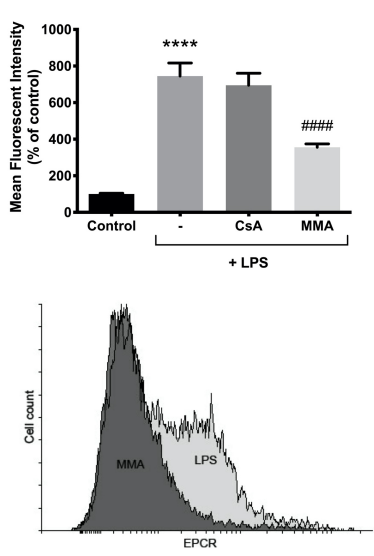

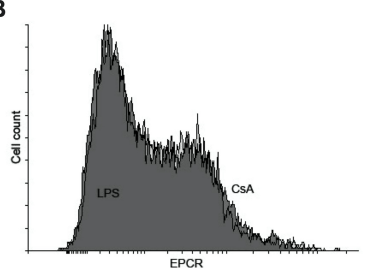

D

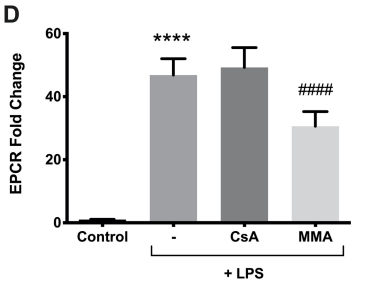

Figure 4. Transcriptional regulatory mechanism of EPCR upon LPS stimulation. (A, B) EPCR protein levels were measured by flow cytometry after CsA and MMA treatment. (C) Mean fluorescent intensity of CsA and MMA on LPS induced EPCR levels. (D) EPCR mRNA levels were measured by real-time PCR. Data are expressed as mean \pm SEM $(n=3) .{ }^{* * * *} p<0.0001$

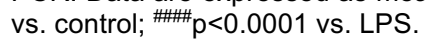

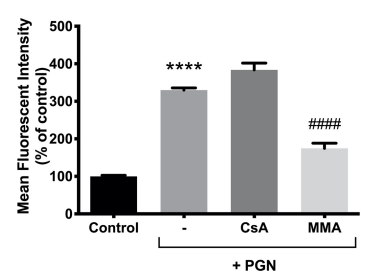

C

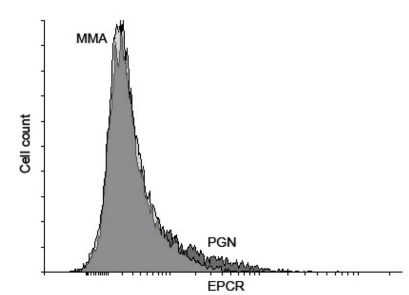

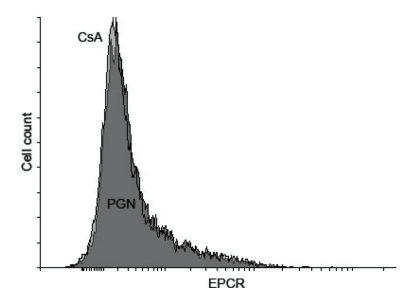

D

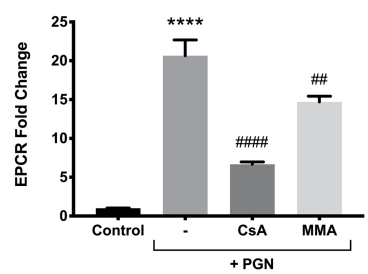

Figure 5. Transcriptional regulatory mechanism of EPCR upon PGN stimulation. (A, B) EPCR protein levels were measured by flow cytometry after CsA and MMA treatment. (C) Mean fluorescent intensity of CsA and MMA on PGN induced EPCR levels. (D) EPCR mRNA levels were measured by real-time PCR. Data are expressed as mean \pm SEM $(n=3)$. ${ }^{* * * *} p<0.0001$ vs.

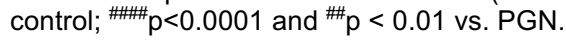

In our study, it has been shown that EPCR is expressed in mRNA and protein levels in the N9 mouse microglia cell line, and LPS, a gram-negative

inflammatory insult, and PGN, a gram-positive inflammatory insult, induce EPCR expression in microglial cells. However, Poly(l:C), a viral infection stimulant, did not cause upregulation of EPCR expression. Also, this effect of LPS was determined by the Sp1 transcription factor in our study. On the other hand, in our experiments with PGN, the EPCR upregulation was mediated by both Sp1 and NFATc1 transcription factors; however, Sp1 revealed a potent effect on the regulation of EPCR.

It has been shown that how EPCR is regulated in microglial cells for the first time in literature. Of APC receptors, it is widely known that PAR1-4 are expressed by microglia (27) and PAR1-2 by astrocytes $(28,29)$. EPCR is the first defined receptor of APC. During developmental stages, knock-out of EPCR results in embryonic lethality (30). The expression of the EPCR receptor is, therefore, of vital importance. The presence of EPCR in the cell membrane of monocytes with the same developmental origin as the microglia cells was shown in 2001 (31). For this reason, it is predictable that the microglia, the immune cells of the central nervous system, express the EPCR receptor. APC can demonstrate cytoprotective and antiinflammatory effects in the central nervous system via the EPCR receptor in glial cells. Basal EPCR expression is highly evident in neutrophil or gastric epithelial cells $(32,33)$. However, in our study, basal EPCR expression in flow cytometry was notably lower than expression in other cells.

It is likely that basal low EPCR expression may increase in microglial cells in inflammatory processes and mediate the effects of APC in inflammation. Therefore, LPS and PGN were used as the inflammatory stimulus in our study. Here we have reported an increase in EPCR expression in N9 microglial cells treated with LPS and PGN. In accordance with a recent study (34), we have confirmed LPS induced upregulation of EPCR. However, when the kidneys were examined in endotoxin-treated mice, an increase in EPCR mRNA levels was shown due to LPS stimulation (35). The increase in EPCR expression is likely to mediate the cytoprotective effects of APC. The cytoprotective effect of endotoxemia requires the activation of the EPCR receptor pathway (36). In the absence of EPCR expression, an increase in inflammatory response was observed in the heart tissue following 
LPS stimulation (10). Furthermore, it was observed that after LPS stimulation, mice produced more cytokines in the absence of EPCR (37), suggesting that EPCR expression might negatively regulate inflammatory responses.

Our findings are significant in terms of EPCR expression's role in regulating inflammatory responses in the brain. In EPCR overexpressing Tie2-EPCR transgenic mice, LPS stimulation was reported to increase survival compared to wild-type mice, demonstrating the importance of EPCR expression in the immune response (11). EPCR expression has an essential role in preventing vascular escape in response to inflammation. Genetically modified mice expressing EPCR $10 \%$ less or anti-EPCR are associated with increased vascular damage (38). Elevated EPCR levels in endothelial cells express and secrete a decreased amount of pro-inflammatory molecules (8).

Nevertheless, there is no study reporting the changes in EPCR levels due to PGN stimulation of microglial cells in the literature. As far as we are aware, this is the first time that PGN induced EPCR expression in microglial cells. Thus, our data suggest that the LPS and PGN-induced elevation of EPCR in microglia may have a potentially protective role in response to inflammatory stimuli.

To determine the transcription factors regulating EPCR expression, we utilized small molecule inhibitors for Sp1 (29) and NFATc1 (39) which are strong candidates for transcriptional regulators. Sp1 has been first shown to be a trans-acting regulatory element of EPCR (40). A recent study has reported that aldosterone caused increased EPCR protein levels in human arterial endothelial cells via activating the Sp1 transcription factor (41). Besides, NFATc1 was also shown to be a regulatory element of EPCR expression recently (26). It was also reported that balloon injury caused upregulation of EPCR in aortic smooth muscle tissues, and inhibition of NFATc1 by CsA reversed the upregulated EPCR levels (26). In our study, when we inhibited NFATc1 by CsA, we found no decrease in LPS-induced EPCR mRNA and protein levels, whereas inhibition of Sp1 with MMA reversed the upregulation of EPCR significantly. Moreover, upon inhibition of NFATc1 by CsA or Sp1 with MMA in PGN induced inflammation, EPCR expression was downregulated in both conditions, suggesting that PGN may induce EPCR expression in both NFATc1- and Sp1-dependent manner.

The present study makes several noteworthy contributions to the regulation of the EPCR pathway in microglial inflammatory responses. For the first time, our study revealed how EPCR was regulated in microglial cells upon bacterial inflammation. It was also determined that EPCR expression in microglial cells increased with LPS and PGN, which was dependent on the Sp1 transcription factor. Further experimental investigations are needed to estimate the effects of LPS and PGN on Sp1 activation or nuclear translocation.

Conflict of interest: The authors declare that there is no conflict of interest regarding the publication of this paper.

Funding: This study received financial support from The Scientific and Technological Research Council of Turkey (TUBITAK) (Project number 114Z577).

Acknowledgments: The authors thank Dr. Erden Eren for his technical assistance.)

Peer-review: Externally peer-reviewed.

\section{REFERENCES}

1. Fukudome K, Esmon CT. Molecular cloning and expression of murine and bovine endothelial cell protein C/activated protein $C$ receptor (EPCR). The structural and functional conservation in human, bovine, and murine EPCR. J Biol Chem. 1995;270(10):5571-5577.

2. Esmon CT. The normal role of Activated Protein C in maintaining homeostasis and its relevance to critical illness. Crit Care. 2001;5(2):S7-12.

3. Esmon CT. Inflammation and the activated protein C anticoagulant pathway. Semin Thromb Hemost. 2006;32 Suppl 1:49-60.

4. Esmon CT. Crosstalk between inflammation and thrombosis. Maturitas. 2004;47(4):305-314.

5. Gleeson EM, O'Donnell JS, Preston RJ. The endothelial cell protein $C$ receptor: cell surface conductor of cytoprotective coagulation factor signaling. Cell Mol Life Sci. 2012;69(5):717-726.

6. Iwasaki H, Arai F, Kubota $Y$, Dahl M, Suda T. Endothelial protein $C$ receptor-expressing hematopoietic stem cells reside in the perisinusoidal niche in fetal liver. Blood. 2010;116(4):544-553.

7. Park SY, Lee HE, Li H, Shipitsin M, Gelman R, Polyak K. Heterogeneity for stem cell-related markers according to tumor subtype and histologic stage in breast cancer. Clin Cancer Res. 2010;16(3):876-887. 
8. Murakami K, Okajima K, Uchiba M, et al. Activated protein $\mathrm{C}$ prevents LPS-induced pulmonary vascular injury by inhibiting cytokine production. Am J Physiol. 1997;272(2 Pt 1):L197-202.

9. Yuksel M, Okajima K, Uchiba M, Horiuchi S, Okabe H. Activated protein C inhibits lipopolysaccharideinduced tumor necrosis factor-alpha production by inhibiting activation of both nuclear factor-kappa B and activator protein-1 in human monocytes. Thromb Haemost. 2002;88(2):267-273.

10.Iwaki T, Cruz DT, Martin JA, Castellino FJ. A cardioprotective role for the endothelial protein $C$ receptor in lipopolysaccharide-induced endotoxemia in the mouse. Blood. 2005;105(6):2364-2371.

11.Li W, Zheng X, Gu J, et al. Overexpressing endothelial cell protein $C$ receptor alters the hemostatic balance and protects mice from endotoxin. J Thromb Haemost. 2005;3(7):13511359.

12.Mosnier LO, Griffin JH. Inhibition of staurosporineinduced apoptosis of endothelial cells by activated protein $C$ requires protease-activated receptor-1 and endothelial cell protein $\mathrm{C}$ receptor. Biochem $\mathrm{J}$. 2003;373(Pt 1):65-70.

13.Feistritzer C, Riewald M. Endothelial barrier protection by activated protein $C$ through PAR1dependent sphingosine 1-phosphate receptor-1 crossactivation. Blood. 2005;105(8):3178-3184.

14.Bae JS, Yang L, Manithody C, Rezaie AR. The ligand occupancy of endothelial protein $C$ receptor switches the protease-activated receptor 1dependent signaling specificity of thrombin from a permeability-enhancing to a barrier-protective response in endothelial cells. Blood. 2007;110(12):3909-3916.

15. Nayak RC, Sen P, Ghosh S, et al. Endothelial cell protein $C$ receptor cellular localization and trafficking: potential functional implications. Blood. 2009;114(9):1974-1986.

16. Nayak RC, Keshava S, Esmon CT, Pendurthi UR, Rao LV. Rab GTPases regulate endothelial cell protein $C$ receptor-mediated endocytosis and trafficking of factor VIla. PLoS One. 2013;8(3):e59304.

17. Griffin JH, Zlokovic BV, Mosnier LO. Protein C anticoagulant and cytoprotective pathways. Int $\mathrm{J}$ Hematol. 2012;95(4):333-345.

18. Thiyagarajan M, Fernandez JA, Lane SM, Griffin $\mathrm{JH}$, Zlokovic BV. Activated protein C promotes neovascularization and neurogenesis in postischemic brain via protease-activated receptor 1. J Neurosci. 2008;28(48):12788-12797.

19. Zlokovic BV, Zhang C, Liu D, Fernandez J, Griffin $\mathrm{JH}$, Chopp M. Functional recovery after embolic stroke in rodents by activated protein C. Ann Neurol. 2005;58(3):474-477.

20.Guo H, Liu D, Gelbard H, et al. Activated protein C prevents neuronal apoptosis via protease activated receptors 1 and 3 . Neuron. 2004;41(4):563-572.

21.Zhong Z, Ilieva H, Hallagan L, et al. Activated protein $\mathrm{C}$ therapy slows ALS-like disease in mice by transcriptionally inhibiting SOD1 in motor neurons and microglia cells. J Clin Invest. 2009;119(11):3437-3449.

22. Deane R, LaRue B, Sagare AP, Castellino FJ, Zhong Z, Zlokovic BV. Endothelial protein C receptor-assisted transport of activated protein $C$ across the mouse blood-brain barrier. J Cereb Blood Flow Metab. 2009;29(1):25-33.

23. Righi M, Mori L, De Libero G, et al. Monokine production by microglial cell clones. Eur J Immunol. 1989;19(8):1443-1448.

24.Livak KJ, Schmittgen TD. Analysis of relative gene expression data using real-time quantitative PCR and the 2(-Delta Delta $\mathrm{C}(\mathrm{T})$ ) Method. Methods. 2001;25(4):402-408.

25. Gu JM, Fukudome K, Esmon CT. Characterization and regulation of the 5'-flanking region of the murine endothelial protein $\mathrm{C}$ receptor gene. J Biol Chem. 2000;275(17):12481-12488.

26.Lee MY, Garvey SM, Ripley ML, Wamhoff BR. Genome-wide microarray analyses identify the protein $C$ receptor as a novel calcineurin/nuclear factor of activated $\mathrm{T}$ cells-dependent gene in vascular smooth muscle cell phenotypic modulation. Arterioscler Thromb Vasc Biol. 2011;31(11):2665-2675.

27. Balcaitis S, Xie Y, Weinstein JR, et al. Expression of proteinase-activated receptors in mouse microglial cells. Neuroreport. 2003;14(18):23732377.

28.Bushell TJ, Plevin R, Cobb S, Irving AJ. Characterization of proteinase-activated receptor 2 signalling and expression in rat hippocampal neurons and astrocytes. Neuropharmacology. 2006;50(6):714-725.

29.Ubl JJ, Reiser G. A novel proteolytic mechanism for termination of the CA2+ signalling evoked by proteinase-activated receptor-1 (PAR-1) in rat astrocytes. Adv Exp Med Biol. 2000;477:323-329. 
30. Esmon CT. The endothelial protein C receptor. Curr Opin Hematol. 2006;13(5):382-385.

31.Galligan L, Livingstone W, Volkov $Y$, et al. Characterization of protein $\mathrm{C}$ receptor expression in monocytes. Br J Haematol. 2001;115(2):408414.

32. Nakamura M, Gabazza EC, Imoto I, et al. Antiinflammatory effect of activated protein $C$ in gastric epithelial cells. J Thromb Haemost. 2005;3(12):2721-2729.

33.Sturn DH, Kaneider NC, Feistritzer C, Djanani A, Fukudome K, Wiedermann CJ. Expression and function of the endothelial protein $\mathrm{C}$ receptor in human neutrophils. Blood. 2003;102(4):14991505.

34.Shavit Stein E, Ben Shimon M, Artan Furman A, Golderman V, Chapman J, Maggio N. Thrombin Inhibition Reduces the Expression of Brain Inflammation Markers upon Systemic LPS Treatment. Neural Plast. 2018;2018:7692182.

35.Song D, Ye X, Xu H, Liu SF. Activation of endothelial intrinsic NF-\{kappa\}B pathway impairs protein $\mathrm{C}$ anticoagulation mechanism and promotes coagulation in endotoxemic mice. Blood. 2009;114(12):2521-2529.

36.Kerschen EJ, Fernandez JA, Cooley BC, et al. Endotoxemia and sepsis mortality reduction by non-anticoagulant activated protein C. J Exp Med. 2007;204(10):2439-2448.

37.Zheng $X$, Li W, Song $Y$, et al. Non-hematopoietic EPCR regulates the coagulation and inflammatory responses during endotoxemia. J Thromb Haemost. 2007;5(7):1394-1400.

38. von Drygalski A, Furlan-Freguia C, Ruf W, Griffin $\mathrm{JH}$, Mosnier LO. Organ-specific protection against lipopolysaccharide-induced vascular leak is dependent on the endothelial protein $C$ receptor. Arterioscler Thromb Vasc Biol. 2013;33(4):769776.

39.Seol JW, Lee YJ, Jackson CJ, Sambrook PN, Park SY. Activated protein $C$ inhibits bisphosphonateinduced endothelial cell death via the endothelial protein C receptor and nuclear factor-kappaB pathways. Int J Mol Med. 2011;27(6):835-840.

40.Hayashi T, Nakamura H, Okada A, et al. Organization and chromosomal localization of the human endothelial protein $C$ receptor gene. Gene. 1999;238(2):367-373.

41.Lagrange J, Li Z, Fassot C, et al. Endothelial mineralocorticoid receptor activation enhances endothelial protein $\mathrm{C}$ receptor and decreases vascular thrombosis in mice. FASEB J. 2014;28(5):2062-2072. 